\title{
Review
}

\section{The endocannabinoid system, anandamide and the regulation of mammalian cell apoptosis}

\author{
M Maccarrone ${ }^{\star, 1}$ and A Finazzi-Agró ${ }^{2}$ \\ 1 Department of Biomedical Sciences, University of Teramo, Teramo, Italy \\ 2 Department of Experimental Medicine and Biochemical Sciences, University of \\ Rome 'Tor Vergata', Rome, Italy \\ * Corresponding author: M Maccarrone, Department of Biomedical Sciences, \\ University of Teramo, Piazza A Moro 45, Teramo, I-64100 Italy. Tel: + 39- \\ 0861-266875; Fax: + 39-0861-412583; E-mail: Maccarrone@ vet.unite.it.
}

Received 20.2.03; revised 05.5.03; accepted 05.5.03

Edited by $\mathrm{S}$. Orrenius

\begin{abstract}
Endocannabinoids are a new class of lipid mediators, which include amides, esters and ethers of long-chain polyunsaturated fatty acids. Anandamide ( $\mathrm{N}$-arachidonoylethanolamine; $A E A)$ and 2-arachidonoylglycerol (2-AG) are the main endogenous agonists of cannabinoid receptors able to mimic several pharmacological effects of $\Delta$-9-tetrahydrocannabinol, the active principle of Cannabis sativa preparations like hashish and marijuana. The pathways leading to the synthesis and release of AEA and 2-AG from neuronal and non-neuronal cells are still rather uncertain. Instead, it is known that the activity of AEA is limited by cellular uptake through a specific membrane transporter, followed by intracellular degradation by a fatty acid amide hydrolase. Together with AEA and congeners these proteins form the 'endocannabinoid system'. Here, the involvement of AEA in apoptosis and the underlying signal transduction pathways will be reviewed, along with the metabolic routes and the molecular targets of this endocannabinoid. Also, recent findings on the apoptotic potential of AEA for neuronal cell differentiation and brain development will be discussed.

Cell Death and Differentiation (2003) 10, 946-955. doi:10.1038/ sj.cdd. 4401284
\end{abstract}

Keywords: brain development; cannabinoid receptors; cell differentiation; metabolism; neurogenesis; signal transduction; vanilloid receptors

\footnotetext{
Abbreviations: AEA, $\mathrm{N}$-arachidonoylethanolamine (anandamide); 2-AG, 2-arachidonoylglycerol; AMT, anandamide membrane transporter; CB1/2R, type 1/2 cannabinoid receptor; ERK, extracellular signal-regulated kinase; FAAH, fatty acid amide hydrolase; FAK, focal adhesion kinase; $\mathrm{FSH}$, follicle-stimulating hormone; JNK, c-Jun N-terminal kinase; MAPK, mitogen-activated protein kinase; NAPE, $\mathrm{N}$-acylphosphatidylethanolamine; NArPE, $\mathrm{N}$-arachidonoylphosphatidylethanolamine; NGF, nerve growth factor; $\mathrm{NO}(\mathrm{S})$, nitric oxide (synthase); OEA, $N$-oleoylethanolamine; PEA, $N$-palmitoylethanolamine; PKA/B, protein kinase
}

A/B; PI3K, phosphatidylinositol 3-kinase; SEA, $N$-stearoylethanolamine; THC, $\Delta$-9-tetrahydrocannabinol; VR, vanilloid receptor

\section{The Endocannabinoids}

Two main molecular targets of $\Delta$-9-tetrahydrocannabinol (THC; Figure 1), the psychoactive principle of Cannabis sativa, are type 1 and type 2 cannabinoid receptors (CB1R and CB2R). ${ }^{1}$ Both of them were discovered and characterized more than four millennia after the beneficial effects of cannabis extracts had been exploited in folklore medicine. Afterwards, an endogenous THC-like molecule, called anandamide ( $N$-arachidonoylethanolamine; AEA; Figure 1$)$ from 'ananda', the Sanskrit word for 'bliss', was isolated and found to activate $\mathrm{CB}$ receptors, thus mimicking the psychotropic effects of THC. ${ }^{2}$ In a few years other endogenous agonists of CB receptors were characterized, and were collectively called 'endocannabinoids'. ${ }^{3}$ Recently, the biological actions of the endocannabinoids and their implications for human health have been reviewed. ${ }^{4}$ In particular, attention has been focused on the possible role of AEA and other endocannabinoids in regulating cell growth and differentiation, which might account for some pathophysiological effects of these lipids. This paper will focus on the metabolism of AEA and its involvement in apoptosis, and more generally it will discuss the ability of AEA to control cell fate.

Endocannabinoids are lipid mediators, isolated from brain and peripheral tissues, which include amides, esters and ethers of long-chain polyunsaturated fatty acids. ${ }^{2}$ These compounds exhibit 'cannabimimetic activity', that is, they act as 'THC mimetics' in a long series of bioassays described in the literature. ${ }^{5}$ The discovery of AEA in pig brain, and the finding that this compound was cannabimimetic, confirmed the hypothesis of the existence of endogenous ligands for the cannabinoid receptors. Although structurally different from plant cannabinoids, AEA shares critical pharmacophores with THC (Figure 1). Thus, together with its congeners it was termed 'endocannabinoid' in analogy with the 'endorphins', that is, the endogenous ligands of opiate receptors. Another arachidonate derivative, 2-arachidonoylglycerol (2-AG; Figure 1), was shown to mimic THC by functionally activating $\mathrm{CB}$ receptors, and together with $\mathrm{AEA}$ is the endocannabinoid whose biological activity has been best characterized to date. ${ }^{6}$ Recently, a new ether-type endocannabinoid has been added to the cohort of these lipid mediators, that is, 2-arachidonoyl glyceryl ether (noladin ether). ${ }^{7}$ Since ethers are generally stable in vivo, whereas AEA (an amide) and 2-AG (an ester) are rapidly hydrolyzed, noladin ether might lead to drug development. $\mathrm{N}$-palmitoylethanolamine (PEA), $\mathrm{N}$-oleoylethanolamine (OEA) and $N$-stearoylethanolamine (SEA; Figure 1) are 'endocannabinoid-like' compounds that are present in human, mouse and rat brain in considerable amounts. ${ }^{3,4}$ 

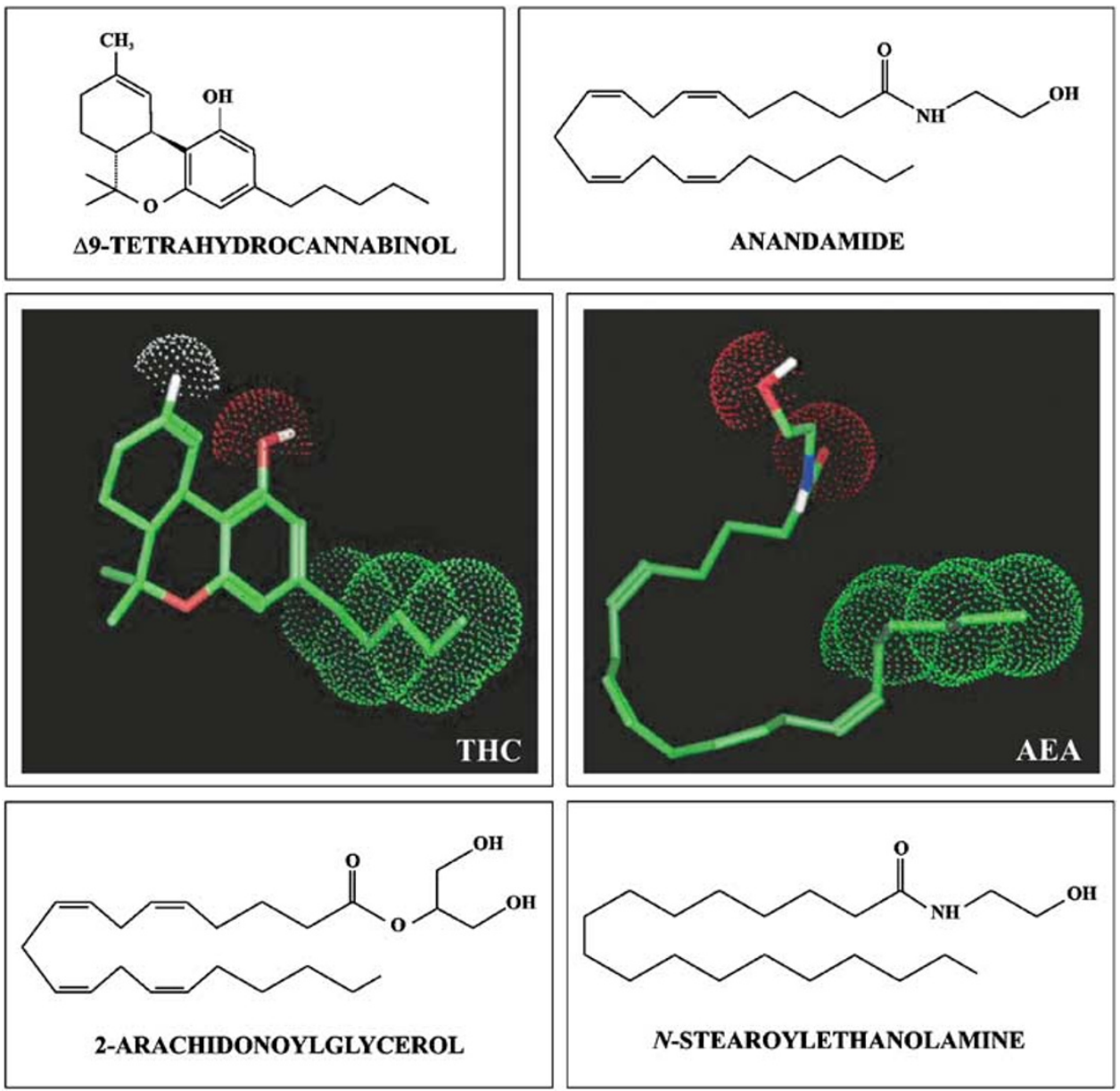

Figure 1 Structure of anandamide and related compounds. The three-dimensional structures of THC and a AEA shown in the middle panels highlight the van der Waals sufaces of the pharmacophores shared by the two compounds (courtesy of Dr Mario van der Stelt, Utrecht University, The Netherlands)

Besides some biological activities, either cannabimimetic or noncannabimimetic, and a potential structural role in lipid bilayers, these 'endocannabinoid-like' molecules can have a further 'entourage effect', that is, they might potentiate the activity of AEA or 2-AG by inhibiting their degradation. ${ }^{2}$ In just one decade, the endocannabinoids have been shown to play manifold roles, both in the central nervous system and in the periphery. Their actions have been recently reviewed, ${ }^{4}$ and are summarized in Table 1 . It seems worth noting that endocannabinoids might act in the central nervous system not only as modulatory substances (i.e. in an autocrine fashion) like eicosanoids and neuropeptides, but also as neurotransmitters. In particular, they are the only neurotransmitters as yet known to act as retrograde synaptic messengers, ${ }^{8,9}$ and the meaning of this retrograde signalling in neuronal networks is still under investigation. On the other hand, AEA has been shown to control the cell choice between growth and death, that is the focus of this review. In addition, the synthetic and degradative routes of AEA will be summarized, whereas the pathways for the biosynthesis and degradation of 2-AG will not be covered, being different from those of $A E A .6,10$ Furthermore, 2-AG and most of the other congeners of AEA do not seem to play a role in the control of cell fate, as discussed later in this review.

\section{Synthesis and Degradation of AEA}

Unlike classical neurotransmitters and neuropeptides, AEA and 2-AG are not stored in intracellular compartments, but are produced on demand by receptor-stimulated cleavage of lipid precursors. The AEA precursor is an $\mathrm{N}$-arachidonoylphosphatidylethanolamine (NArPE), which is believed to originate from the transfer of arachidonic acid (AA) from the sn-1 position of 1,2-sn-di-arachidonoylphosphatidylcholine to phosphatidylethanolamine, catalyzed by a calcium-dependent $N$-acyltransferase (trans-acylase) (Figure 2a). NArPE is then cleaved by a yet uncharacterized $N$-acylphosphatidylethanolamine (NAPE)-specific phospholipase D, which release AEA and phosphatidic acid (Figure 2a). At present, it is not yet clear whether the $N$-acyltransferase or the NAPEspecific phospholipase $D$ controls the rate-limiting step of AEA synthesis. ${ }^{3,4,6,11}$ However, a similar route can be operational also for the synthesis of the other cannabimimetic NAEs, since their precursors, $\mathrm{N}$-acylethanolamine phospholipids, are ubiquitous constituents of animal and human cells, tissues and body fluids. ${ }^{3,11}$

The biological activity of AEA is terminated by its removal from the extracellular space, which occurs through a two-step process: (i) cellular uptake by a high affinity transporter, 
Table 1 Biological actions of AEA and congeners in the central nervous system and in the periphery

\section{Central nervous system}

Thalamus, hypothalamus, hippocampus

Control of pain initiation

Control of the secretion of pituitary hormones

Control of wake/sleep cycles

Control of thermogenesis

Control of appetite

Control of synaptic plasticity

Impairment of working memory and of memory

consolidation, possibly due to interference with

acetylcholine release

Inhibition of long-term potentiation

Inhibition of glutamatergic transmission

Basal ganglia, striatum, globus pallidus

Control of psychomotor disorders

Interference with dopaminergic transmission

Inhibition of dopamine synthesis and/or release

Inhibition of $\gamma$-aminobutyric acid (GABA)ergic

transmission

Interference with dopaminergic transmission

Potentiation of $\gamma$-aminobutyric acid (GABA)-

mediated catalepsy

Suppression of locomotion

\section{Periphery}

Cardiovascular system

Profound decrease in blood pressure

(hypotension) and heart rate (bradycardia)

Reduction of sympathetic tone due to inhibition of norepinephrine release

Induction of hypotension during hemorrhagic shock

Induction of hypotension during endotoxic shock Vasodilation

Platelet aggregation

\author{
Immune system \\ Repression of interleukin-2 (IL-2) transcription \\ and secretion \\ Stimulation of interleukin-6 (IL-6) synthesis \\ Inhibition of tumor necrosis factor $\alpha$ (TNF- $\alpha$ ) \\ production \\ Inhibition of interferon $\gamma$ (IFN- $\gamma$ ) synthesis \\ Downregulation of rat mast cell activation \\ Stimulation of hematopoietic cell growth \\ Inhibition of leukemia inhibitory factor (LIF) \\ release \\ Downregulation of airway hyper-reactivity \\ Stimulation of serotonin release \\ Inhibition of neutrophil recruitment \\ Reproductive system \\ Developmental arrest at the stage of two-cell \\ embryos \\ Inhibition of zona hatching of blastocysts, and of \\ implantation \\ Acceleration of trophoblast differentiation and \\ outgrowth (low doses of endocannabinoids) \\ Inhibition of trophoblast differentiation (high \\ doses of endocannabinoids) \\ Digestive tract \\ Inhibition of peristalsis \\ Inhibition of intestinal motility
}

Cortex, cerebellum, spinal cord

Blockade of $\mathrm{N}$-methyl-D-aspartate (NMDA)

receptors

Control of tremor and spasticity

Retina

Control of scotopic vision followed by (ii) intracellular degradation by a fatty acid amide hydrolase (Figure $2 \mathrm{~b}$ ). Several properties of a selective AEA membrane transporter (AMT) have been characterized, although its molecular structure remains unknown. ${ }^{12} \mathrm{AMT}$ has been shown to take up AEA according to a saturable process, which has the characteristics of a facilitated diffusion: it is bidirectional and independent on both energy and sodium, unlike amine and amino-acid transporters. Moreover, the use of different analogues has led to some generalizations on the properties of AMT: (i) at least one cis double bond in a long alkyl chain must be present for binding; (ii) the AEA binding site can tolerate very bulky additions to the head group region, provided they are hydrophobic; and (iii) aromatic substitutions in the head group region stabilize the binding to the carrier, possibly because of the introduction of aromatic stacking interactions. ${ }^{12}$ Recently, AMT has been shown to be functionally coupled to $C B 1$ receptors through nitric oxide (NO): activation of $C B 1$ receptors by $A E A$ releases $\mathrm{NO}$, which in turn activates AMT (perhaps by nitrosylating a cysteine residue at the binding site), thus stimulating the removal of $A E A$ from the extracellular space. ${ }^{4}$ This regulatory loop represents a 'timer', by which activation of $C B 1$ receptors by $A E A$ triggers the termination of the activity of $A E A$ at the receptor itself. $A$ feature of $A M T$ that deserves further investigation is its ability to 'work in reverse', that is, to extrude AEA outside the cell. This activity, recently demonstrated in human endothelial cells, ${ }^{13}$ might be critical in regulating $A E A-m e d i a t e d$ retrograde signalling. ${ }^{8,9}$

Once taken up by the cells, AEA is a substrate for the enzyme fatty acid amide hydrolase ( $N$-arachidonoylethanolamine amidohydrolase, EC 3.5.1.4; FAAH), which breaks the amide bond and releases AA and ethanolamine (Figure $2 b$ ). $\mathrm{FAAH}$ has been recently crystallized and its three-dimensional structure has been analyzed at a $2.8 \AA$ resolution. ${ }^{14}$ FAAH is a membrane-bound enzyme found mainly in microsomal and mitochondrial fractions, and also shows an esterase activity. ${ }^{15}$ It has been proposed that FAAH controls the cellular uptake of AEA, by creating and/or maintaining an inward concentration gradient that drives the facilitated diffusion of AEA through AMT. ${ }^{16}$ Although FAAH is not the only factor controlling $A E A$ transport, ${ }^{17}$ its pivotal role in $A E A$ degradation may explain why it is modulated in several pathophysiological conditions. ${ }^{4}$ In this context, it should be pointed out that the relationship between AMT and FAAH is still under debate, because FAAH might not quite need a transporter to get in contact with $\mathrm{AEA} .{ }^{14}$ At any rate, three domains have been identified in FAAH: (i) a transmembrane domain at the $\mathrm{N}$ terminus, which does not affect enzyme 
a

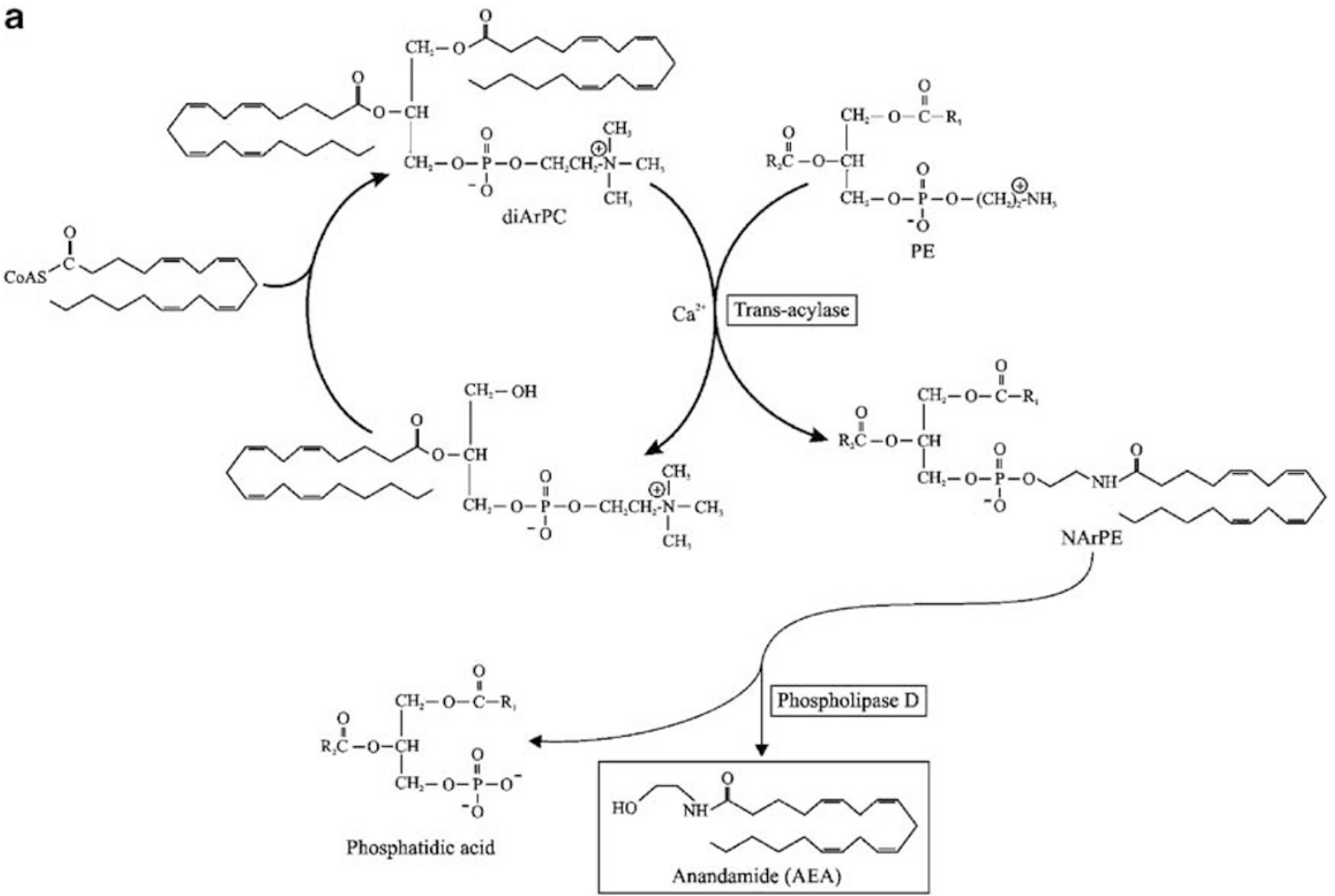

b

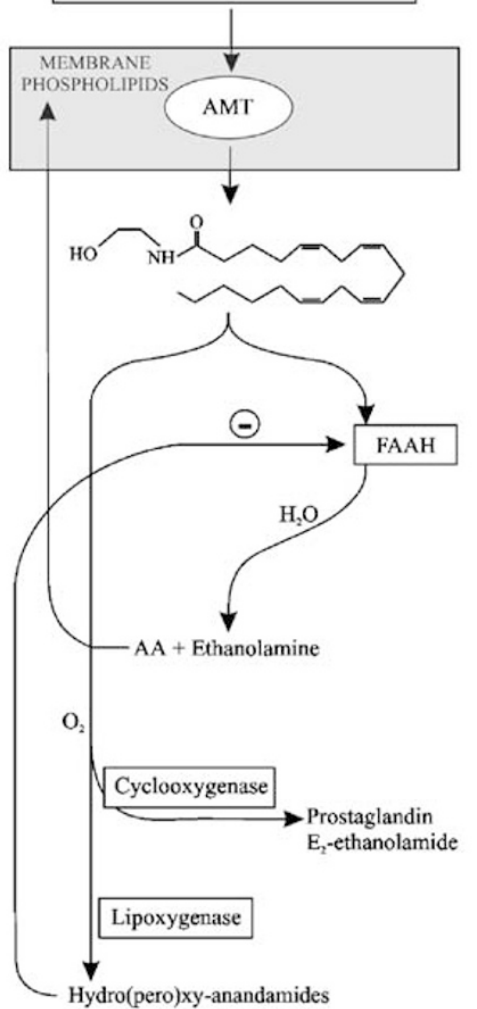

Figure 2 Synthesis and degradation of anandamide. a) Membrane NArPE is formed by the transfer of AA from the sn-1 position of 1,2-sn-diarachidonoylphosphatidylcholine (diArPC) to phosphatidyl-ethanolamine (PE), catalyzed by a calcium-dependent $\mathrm{N}$-acyltransferase (trans-acylase). Hydrolysis of NArPE by a yet uncharacterized phospholipase $D$ releases $A E A$ and phosphatidic acid. b) AEA is transported into the cell by an AMT and, once taken up, is hydrolyzed by fatty acid amide hydrolase (FAAH). Alternatively, AEA can be oxidized by the enzymes of the 'arachidonate cascade': COX, which generates a prostaglandin $E_{2}$ ethanolamide, or lipoxygenase, which produces hydro(pero)xy-anandamides able to back inhibit FAAH. AA released from AEA is immediately reincorporated into membrane lipids 
Molecular target

'Classical' cannabinoid (CB1 or CB2) receptors
Signals involved

Inhibition of adenylyl cyclase (i.e. of forskolininduced cAMP formation)

Inhibition of L-type, N-type and P/Q-type $\mathrm{Ca}^{2+}$ channels

Activation of inwardly rectifying $\mathrm{K}^{+}$channels

Activation of the MAPK pathway

Activation of cytosolic phospholipase $\mathrm{A}_{2}$

Activation of neuronal FAK

Activation of NOS

'Nonclassical'(non-CB1/non-CB2) cannabinoid receptors $(\mathrm{CBn})$

Noncannabinoid receptors and/or nonreceptormediated actions

Vanilloid (VR1) receptors
Release of AA

Activation of the MAPK pathway

Inhibition of gap junction activity

Inhibition of gap junction-mediated and

glutamate-triggered $\mathrm{Ca}^{2+}$ waves

Inhibition of shaker-related voltage-gated $\mathrm{K}^{+}$ channels

Inhibition of serotonin $5-\mathrm{HT}_{3 \mathrm{~A}}$ receptors

Inhibition of serotonin 5- $\mathrm{HT}_{3 \mathrm{~A}}$ receptor-mediated

currents

Activation of serotonin $5-\mathrm{HT}_{2 \mathrm{~A}}$ receptors

Activation of NMDA- mediated $\mathrm{Ca}^{2+}$ currents

Release of AA

Activation of protein kinase $\mathrm{C}$

Activation of nonselective ion channels

Activation of protein kinase $A$

Rise in intracellular $\mathrm{Ca}^{2+}$

Mitochondrial uncoupling
Inhibition of L-type $\mathrm{Ca}^{2+}$ channels activity but directs protein oligomerization; (ii) a serine- and glycine-rich domain, which contains a typical 'amidase signature' sequence and spans the residues 215-257 in mammalian FAAH; and (iii) a proline-rich domain, which is homologous to the class II SH3-binding domain. ${ }^{14}$ As for the cataytic mechanism, site-directed mutagenesis has demonstrated that a serine (S241) is the catalytic nucleophile in the active site of $\mathrm{FAAH}$, although the enzyme does not show the typical serine-histidine-aspartic acid triad found in serine proteases. ${ }^{14} \mathrm{~A}$ lysine residue (K142) is also critical for the catalytic activity of $\mathrm{FAAH}$, and a single isoleucine residue (1491) has been shown to dictate the strong preference of this enzyme for acyl chains at least nine carbons long. ${ }^{14}$ Its seems worth noting that the hydro(pero)xides generated from AEA by lipoxygenase (LOX) activity were found to inhibit FAAH with apparent inhibition constants in the low micromolar range. ${ }^{18}$ These hydro(pero)xy-anandamides are the most powerful natural inhibitors of FAAH as yet discovered, and since they may be formed in vivo they might play a role in controlling AEA degradation (Figure $2 \mathrm{~b}$ ). On the other hand, the products of AEA generated by cyclooxygenase(COX)-2 do not seem to affect $\mathrm{FAAH}$ activity. ${ }^{18}$

\section{Molecular Targets and Signalling Pathways}

The molecular targets of $A E A$ and 2-AG are the CB1 cannabinoid receptors, present mainly on central and peripheral neurons, the CB2 cannabinoid receptors ex- pressed predominantly by immune cells, the non-CB1/nonCB2 cannabinoid receptors, the noncannabinoid receptors and the vanilloid receptors. $1,3,5$

$\mathrm{CB} 1$ and $\mathrm{CB} 2$ receptors belong to the family of the 'seven trans-membrane spanning receptors', and are coupled to G proteins, particularly those of the $\mathrm{G}_{\mathrm{i} / \mathrm{o}}$ family. ${ }^{1,3,5}$ Recently, the domains of the $C B 1$ receptor which interact with different $G$ protein subtypes have been identified. ${ }^{19}$ Signal transduction pathways regulated by $C B$ receptor-coupled $G$ proteins include the inhibition of adenylyl cyclase, the regulation of ionic currents (inhibition of voltage-gated L-, N- and P/Q-type $\mathrm{Ca}^{2+}$ channels, activation of $\mathrm{K}^{+}$channels), the activation of focal adhesion kinase (FAK), of mitogen-activated protein kinase (MAPK), of cytosolic phospholipase $A_{2}$ and of nitric oxide synthase (NOS), and others summarized in Table 2. $A E A$ and 2-AG show higher affinity for the CB1 than for the CB2 receptor and structure-activity relationship studies have suggested either that only acyl chains that can assume a tightly folded (U-shaped) conformation can bind to CB1 receptors, or that ligand flexibility is very important for this binding. ${ }^{20}$ Binding to $\mathrm{CB} 1$ receptor requires that the endocannabinoid should have an aliphatic chain of 20-22 carbons, with at least three nonconjugated cis double bonds with a saturated tail of at least the last five carbons. ${ }^{20}$ The head group can be either polar or nonpolar but should not be bulky. In the absence of X-ray crystallographic and nuclear magnetic resonance data, suitably tailored molecular probes have shed light on the structural requirements for ligand-receptor interactions. ${ }^{21}$ In general, after activation CB1 receptors undergo phosphorylation and internalization, which may be 
followed by recycling into the membrane if the time of treatment is short. Evidence has emerged that in addition to CB1 and CB2 receptors there are other molecular targets through which the endocannabinoids might induce a biological activity, as listed in Table 2. In particular, a new target of AEA which is attracting great interest is the type 1 vanilloid receptor (VR1), a 'six trans-membrane spanning protein' with intracellular $\mathrm{N}$ - and $\mathrm{C}$-terminals and a pore loop between the fifth and sixth transmembrane helices. ${ }^{22}$ VR1 is activated by vanilloid ligands like capsaicin, but also by noxious stimuli like heat and acids, and thus it can be viewed as a molecular integrator of noxious stimuli in peripheral terminals of primary sensory neurons. ${ }^{23}$ In the last 3 years, a number of studies have pointed towards a physiological role for AEA as VR1 agonist, leading to the concept that AEA, besides being an endocannabinoid, is also a true 'endovanilloid'. ${ }^{22,24}$ Activation of VR1 by binding of AEA to a cytosolic side ${ }^{24}$ triggers the intracellular responses listed in Table 2.

\section{Involvement of AEA and Congeners in Apoptosis}

An antiproliferative action of $A E A$ has been reported in human breast carcinoma cells, arrested at the $\mathrm{G}_{1} / \mathrm{S}$ transition. ${ }^{25}$ This effect of AEA was due to a CB1-like receptor-mediated inhibition of adenylate cyclase and activation of extracellular signal-regulated kinase (ERK). ${ }^{26}$ The signalling pathways linked to these two enzymes led to a lower expression of both the high-molecular weight form of the prolactin receptor ${ }^{25}$ and the high -affinity trk neurotrophin receptor in the cells, ${ }^{27}$ thus resulting in growth arrest. The antitumor effect of AEA has been recently demonstrated also in vivo, where it implicates inhibition of the activity of the K-ras oncogene product, $\mathrm{p} 21^{\mathrm{ras}}$, thereby leading to the inhibition of the ras cascade-dependent tumor growth. ${ }^{28}$ Also an activation of cell proliferation by AEA has been instead reported in hematopoietic cell lines, ${ }^{29}$ but since then it was not extended to other cellular models. Instead, preliminary evidence that the immunosuppressive effects of AEA might be associated with inhibition of lymphocyte proliferation and induction of programmed cell death has been reported, ${ }^{30}$ while growing evidence is being collected, suggesting that AEA might have indeed proapoptotic activity in vitro. ${ }^{31}$ This would extend to endocannabinoids previous observations on $\Delta$-9-tetrahydrocannabinol, shown to induce apoptosis in glioma tumors in vivo, ${ }^{32}$ as well as in glioma cells, ${ }^{33}$ primary neurons, ${ }^{34}$ hippocampal slices ${ }^{34}$ and prostate cells. ${ }^{35}$ However, the mechanism(s) of AEA-induced apoptosis remain(s) to be elucidated.

The proapoptotic activity of AEA in different cellular models has been shown to occur through the activation of different receptors, which in turn trigger the signal transduction pathways schematically depicted in Figure 3 . On the one hand, programmed death of glioma cells in vitro has been shown to involve activation of CB1 receptors followed by ceramide accumulation and Raf1/ERK activation, ${ }^{32}$ on the other hand, the activation of $\mathrm{CB} 2$ receptors seems the critical event leading to inhibition of glioma growth in vivo. ${ }^{36}$ In rat cortical astrocytes and human astrocytoma cells, AEA activates $\mathrm{CB} 1$ receptors leading to sphingomyelin breakdown through the adaptor protein FAN, suggesting a CB1 receptormediated proapoptotic signalling independent of $\mathrm{G}_{\mathrm{i} / \mathrm{o}}$ proteins. ${ }^{37}$ In the same cells, CB1 receptor activation also leads to long-term activation of c-Jun N-terminal kinase (JNK) and p38 MAPK, suggesting that a threshold might exist above which endocannabinoid-induced JNK and p38 MAPK activation would lead to cell death. ${ }^{38}$ More generally, it may be speculated that $A E A$ binding to $C B 1$ receptors modulates the balance among ERK, JNK and p38 MAPK, thus regulating the cell choice between proliferation and death. In addition, it has been proposed that the first peak of ceramide involving FANdependent stimulation of the neutral sphingomyelinase and occurring within minutes, does not play a critical role in cannabinoid-induced apoptosis, compared to the 'long term' increase in ceramide occurring within days. ${ }^{32}$ This second peak is due to de novo synthesis of ceramide through activation of serine palmitoyltransferase. ${ }^{39}$ Besides the modulation of ceramide synthesis and degradation, it has been shown that cannabinoids are able to modulate, again through CB1 receptors, the phosphatidylinositol 3-kinase/ protein kinase $B(P I 3 K / P K B)$ pathway, which serves as a pivotal antiapoptotic signal. ${ }^{40,41}$ This finding is of particular interest, because it points towards a protective role of cannabinoid receptors against programmed cell death, a concept that has found new grounds in human astrocytoma cells. ${ }^{42}$ The first demonstration that activation of cannabinoid receptors by AEA had a protective role was reported in human neuroblastoma and lymphoma cells, where AEA was shown to induce apoptosis through vanilloid receptors. ${ }^{43}$ This effect of AEA occurs through a series of events including increased intracellular calcium concentration, activation of the arachidonate cascade along the COX and the LOX pathways, uncoupling of mitochondria and release of cytochrome $c$, and activation of caspases 3 and $9 .{ }^{43}$ It is remarkable that some of these events are typical of different, unrelated proapoptotic stimuli, ${ }^{44}$ which suggests that AEA shares with other inducers common signalling pathways.

On the other hand, it seems worth noting that AEA exerts a proapoptotic activity by binding to vanilloid receptors and an antiapoptotic action by binding to cannabinoid receptors. Yet, it remains to be clarified if the different localization of the binding sites of these receptors (intracellular for VR1 and extracellular for $\mathrm{CBR}$ ) plays a role in discriminating the opposite effects of AEA on cell death. It is tempting to speculate that modulation of intracellular and extracellular levels of AEA through fine tuning of FAAH (and possibly of AMT) activity is a 'checkpoint', as suggested by several observations on the pivotal role of this enzyme in controlling AEA metabolism. ${ }^{4,14}$ At any rate, of interest is the finding that activation of CB1 (in neuronal cells) or CB2 (in immune cells) receptors prevents $A E A$-induced apoptosis, ${ }^{43}$ a concept that has been extended to different models of programmed cell death. ${ }^{40-42}$ In the same line, an interesting observation has recently shown that activation of $\mathrm{CB} 1$ receptors protects rat glioma cells against HIV-1 Tat-induced cytotoxicity. ${ }^{45}$ The relative involvement of cannabinoid and vanilloid receptors in the induction of apoptosis by AEA has been recently investigated also in rat glioma cells, where the proapoptotic effect of AEA through activation of VR1 has been confirmed together with oxidative stress induction and calpain activa- 


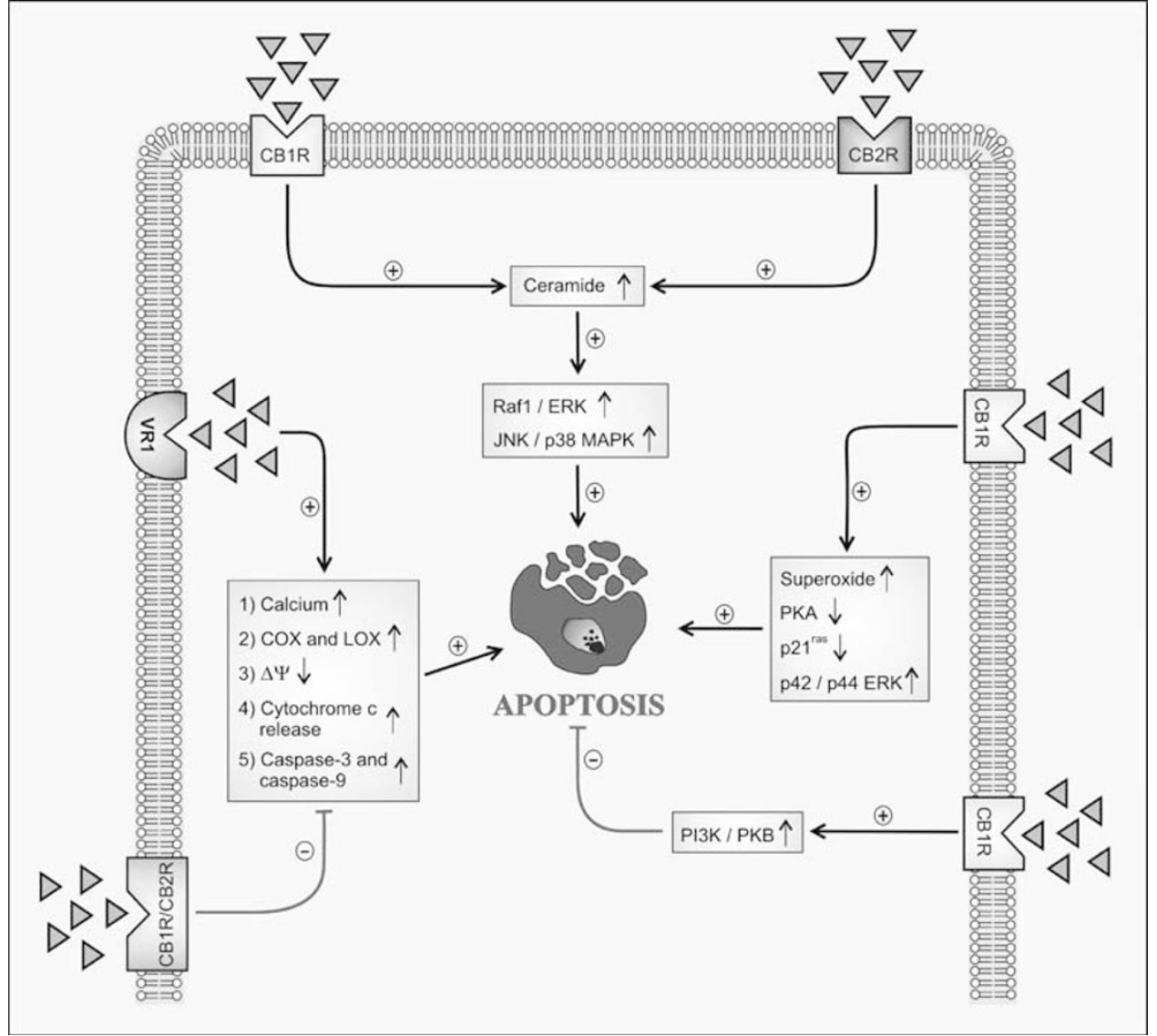

Figure 3 AEA, cannabinoid receptors, vanilloid receptors and apoptosis. Binding of extracellular anandamide (triangles) to type 1 or 2 cannabinoid receptors (CB1R or $\mathrm{CB} 2 \mathrm{R}$ ) triggers different signal transduction pathways, depending on the cell type. Activation of either CB1R or CB2R increases intracellular levels of ceramide, which activates Raf1/ERK cascade, thus engaging JNK/p38 MAPK along the pathway leading to apoptosis. In addition, binding of anandamide to CB1R can trigger superoxide ion production, inhibition of protein kinase A (PKA) and of the K-ras oncogene product p21 $1^{\text {ras }}$, and activation of p42/p44 ERK, all leading to apoptosis. Alternatively, anandamide can activate VR1 by binding to an intracellular site, thus triggering a proapoptotic series of events including elevation of intracellular calcium, activation of the arachidonate cascade through the COX and the LOX pathways, drop in mitochondrial potential $(\Delta \Psi)$, increased release of cytochrome $c$ and activation of caspase-3 and caspase-9. These effects of AEA at VR1 are prevented by simultaneous activation of CB1R (in neuronal cells) or CB2R (in immune cells). In astrocytes, CB1R activation by anandamide can also activate the PI3K/PKB pathway, resulting in protection against apoptosis

tion. ${ }^{46}$ The latter finding is in keeping with the notion that $A E A-$ induced apoptosis in rat pheochromocytoma $\mathrm{PC} 12$ cells requires $\mathrm{CB} 1$ receptor-mediated production of superoxide anions. ${ }^{31}$ In this context, it should be recalled that LOX, a redox stress sensor implicated in various death programs, generates AEA hydro(pero)xides that inhibit the degradation of $A E A$ itself. ${ }^{18}$ Therefore, it can be proposed that these compounds might play a role in the redox balance controlling the apoptotic activity of AEA.

That the oxidative metabolism of AEA might be critical in controlling its proapoptotic potential could hold true also in mouse Sertoli cells, where follicle-stimulating hormone (FSH) has been demonstrated to reduce AEA-induced apoptosis, by enhancing FAAH activity through an indirect (yet unknown) mechanism. ${ }^{47}$ In Sertoli cells, activation of CB2 receptors prevented apoptosis induced by AEA. ${ }^{47}$ These data, together with the well-established relationship of Sertoli cell number to the total spermatogenic output of the testis, can contribute to the negative effects exerted on testicular development by altered FSH concentrations. Incidentally, these findings open a new perspective to the understanding and treatment of male fertility problems, suggesting that the endocannabinoid network plays a role in the hormonal regulation of male fertility. In the same context, a recent report has shown that activation of $\mathrm{CB}$ receptors prevents the growth of skin tumors of mice and humans, by inducing apoptosis and blocking angiogenesis. ${ }^{48}$ Keeping in mind that the incidence of both benign and malignant skin neoplasms has been rising at an alarming rate for the past years, and that nonmelanoma skin cancer is one of the most common malignancies in humans, it can be proposed that local administration of (endo)cannabinoids may constitute a novel therapy for skin tumors.

Unlike AEA, 2-AG, OEA or PEA are not able to modulate cell survival and death, either in human neuronal CHP100 cells or in human lymphoma U937 cells (Figure 4), in keeping with a previous report. ${ }^{43}$ Rat glioma $\mathrm{C} 6$ cells seem to be an exception, because the antiproliferative potency of 2-AG in these cells has been shown to be similar to that of $A E A$, although PEA was ineffective even at 10-fold higher concentrations. ${ }^{46}$ In addition, SEA was almost as effective as AEA in inducing apoptosis (Figure 4), extending previous observa- 
tions on rat glioma $\mathrm{C} 6$ cells. ${ }^{49}$ This finding might be relevant in vivo, because SEA is present in rat, mouse and human brain in even higher amounts than AEA. ${ }^{4}$ While the lack of induction of apoptosis by 2-AG, OEA and PEA is consistent with the fact that these compounds do not activate vanilloid receptors, ${ }^{23}$ the proapoptotic potential of SEA has been shown to occur through a specific binding site different from both VR1 and CBR. ${ }^{49}$ More importantly, a major difference in the proapoptotic activities of AEA and of SEA is that $\mathrm{CB} 1$ receptor activation decreased the former ${ }^{43}$ while increasing the latter. ${ }^{49}$ Since both effects of $\mathrm{CB} 1$ receptors were abolished by the NOS inhibitor L-NAME, and mimicked by the peroxynitrite-donor SIN-1, ${ }^{43,49}$ it can be suggested that NO release associated with $\mathrm{CB} 1$ activation was responsible for the regulation of the apoptotic activity of both endocannabinoids. In fact, NO and even more peroxynitrite reduced the uptake of SEA, thus leading to: (i) slow SEA degradation, (ii) high SEA extracellular concentration, and thus (iii) higher activity of SEA at its binding site. ${ }^{49}$ Conversely, NO and even more peroxynitrite are known to increase $A E A$ import and degradation, thus reducing its activity at CB1 receptors. ${ }^{43}$ However, SEA-induced apoptosis has been shown to occur through the same series of events triggered by $A E A$ at vanilloid receptors (Figure 3 ), suggesting that the different proapoptotic activities of SEA and AEA only depend on their regulation by $\mathrm{NO}$. This opposite regulation of the apoptotic potential of SEA and AEA by NO in neuronal cells needs further investigations that should take into account that NO can also stimulate AEA activity at VR1. ${ }^{24}$ At any rate, it seems worth noting that a human brain tumor -like meningioma has an approximately six-fold smaller content of AEA and related endocannabinoid(-like) compounds than the healthy controls, the levels of 2-AG being equal. ${ }^{4}$ Since a similar decrease was observed in a human glioblastoma, the downregulation of endocannabinoids might normally take place in brain tumors. A lower AEA content and an enhanced expression of cannabinoid receptors, found in malignant cells like transformed thyroid cells ${ }^{28}$ and gliomas, ${ }^{36}$ are indicative of a role of the endocannabinoid system in the tonic suppression of cancer growth. In this context, it seems worth noting that AEA has been proposed also as a new neurotrophin, a type of survival factor that can elicit apoptosis under certain conditions. ${ }^{50}$ Further studies hold the answer about the relative contribution of AEA synthesis, degradation and binding to different receptors to the cell choice between survival or death.

\section{Endocannabinoids and Neuronal Cell Differentiation}

The regulation of neuronal cell survival, death and differentiation is still unclear, but available evidence seems to support a role for endocannabinoids in controlling cell patterns during brain development. ${ }^{51}$ Recently, endocannabinoids have been shown to inhibit neuronal differentiation in various cellular models in vitro, which correlates with their ability to inhibit adult hippocampal neurogenesis in vivo. ${ }^{52}$ These findings might have important biological implications, because the endocannabinoid system plays an active role in normal brain

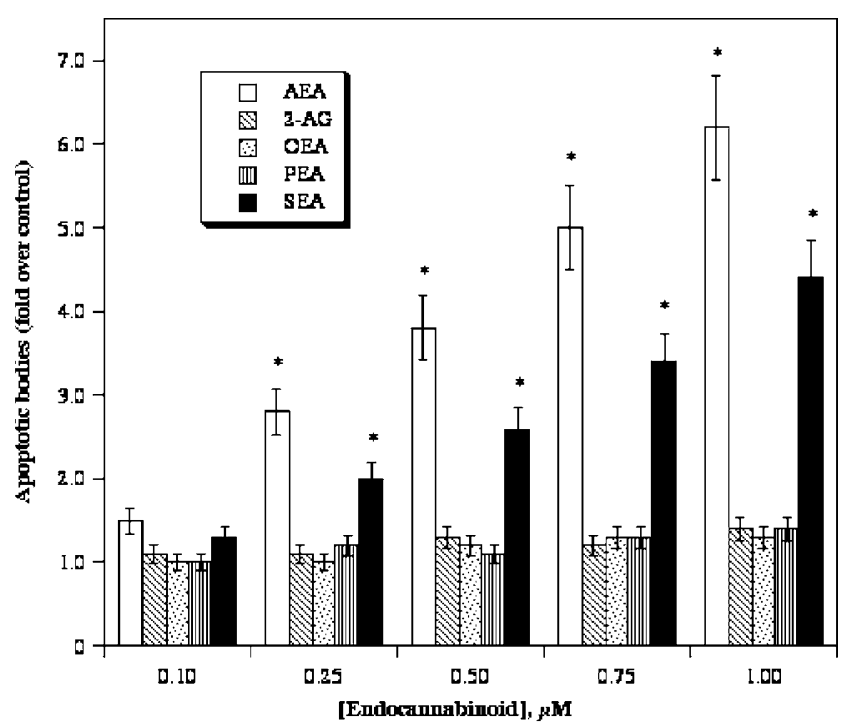

Figure 4 Effect of AEA and congeners on apoptosis of human neuronal and immune cells. Human neuroblastoma CHP100 cells were treated with the indicated concentrations of AEA, 2-AG, OEA, PEA or SEA, then apoptotic body formation was evaluated after $48 \mathrm{~h}$ by cytofluorimetric analysis. Human lymphoma U937 cells showed results superimposable to those obtained with CHP100 cells, omitted for the sake of clarity. Vertical bars indicate S.D. values. *Denotes $P<0.01$ versus vehicle-treated controls ( $P>0.05$ in all other cases)

physiology and its expression follows a defined pattern during brain development. ${ }^{9,51}$ Therefore, besides cannabinoidmediated neuromodulation and inhibition of hippocampal cell firing, ${ }^{9}$ inhibition of neurogenesis in adult hippocampus might help to explain cannabinoid-linked disruption of cognitive processes such as learning and short-term memory. ${ }^{52}$ As far as the mechanism of the antidifferentiating activity of AEA and congeners is concerned, it has been shown that endocannabinoids inhibited in a CB1-dependent manner the ERK signalling pathway, which is responsible for nerve growth factor (NGF) action. $^{52}$ In agreement with this effect, NGFinduced phosphorylation of both the transcription factor Elk, which is essential for neuronal differentiation, and of the TrkA receptor was reduced by $A E A$, which also attenuated NGFinduced Rap1/B-Raf-mediated module that results in sustained ERK activation required for cell differentiation. Taken together, these data demonstrate that endocannabinoids interfere with the NGF signalling responsible for the activation of the differentiation program, that is, they inhibit via $C B 1$ receptors the TrkA-induced Rap1/B-Raf-mediated activation of the ERK signalling pathway. ${ }^{52}$ It should be recalled that activation of $\mathrm{CB} 1$ receptors in human breast cancer cells also leads to the modulation of cell proliferation by inhibiting the expression of NGF receptors. ${ }^{27}$ This finding suggests that the antidifferentiating action of endocannabinoids through interference with NGF signalling might be of more general validity. In this line, current experiments (manuscript in preparation) seem to indicate that $A E A$ inhibits differentiation of human epidermal keratinocytes via a novel CB1dependent signalling pathway that may have important implications for skin development. On the other hand, CB1 stimulation in neurons might also trigger responses like $\mathrm{N}$ cadherin signalling, somewhat opposite to inhibition of neuronal differentiation. ${ }^{53}$ 


\section{Conclusions}

A role for the endogenous cannabinoid system in several aspects of human (patho)physiology has been proposed, through the activation of cannabinoid and vanilloid receptors, and via nonreceptor-mediated actions. In the case of AEA, the control of cell fate seems to be the core of its biological activity. Here, we have described the routes of the synthesis and degradation of $A E A$, and the cellular responses triggered by binding of this lipid to its molecular targets. We have also reviewed the role of AEA and congeners in apoptosis, and have presented the different signal transduction pathways so far involved in this activity. Although present data are still unclear, overall it seems that concomitant (or prevalent) stimulation of vanilloid receptors by AEA leads to proapoptotic effects which are chiefly mediated by MAPK pathways. Recent data on AEA activity in cell differentiation have also been presented. Taken together, the available evidence suggests that AEA and some of its congeners like SEA might play a role as modulators of cell survival and death. These findings, although not yet generalizable, seem to be relevant also from the perspective of acting on the endocannabinoid system in cancer therapy. ${ }^{54}$ Indeed, recent evidence suggests that targeting type 2 cannabinoid receptors can be a novel therapy to treat malignant lymphoblastic diseases. ${ }^{55}$ In this line, investigations aimed at elucidating how the endocannabinoid system is integrated within neuron, hormone and cytokine networks will confirm the relevance of these lipid mediators for human (patho)physiology. Finally, these investigations might impact also the role of endocannabinoids in neuroprotection and neurotoxicity, helping to elucidate how the balance between these opposite effects is controlled. ${ }^{2}$ In this context, the oxidative metabolism of AEA and related compounds might be critical, because it can generate hydro(pero)xy -derivatives with significant affinity for cannabinoid and vanilloid receptors, for membrane transporters like AMT and for hydrolases like FAAH. ${ }^{18}$

\section{Acknowledgements}

We thank Drs. Monica Bari, Natalia Battista and Valeria Gasperi for their expert assistance with the experimental work, and Mr. Graziano Bonelli for excellent production of the artwork. This investigation was supported by Ministero dell'Istruzione, dell'Università e della Ricerca (Cofin 2002) and by Agenzia Spaziale Italiana (contract I/R/098/00), Rome.

\section{References}

1. McAllister SD and Glass $M(2002) \mathrm{CB} 1$ and $\mathrm{CB} 2$ receptor-mediated signalling: a focus on endocannabinoids. Prostaglandins Leukot. Essent. Fatty Acids 66: $161-171$

2. Mechoulam R, Panikashvili D and Shohami E (2002) Cannabinoids and brain injury: therapeutic implications. Trends Mol. Med. 8: 58-61

3. Di Marzo V (1998) 'Endocannabinoids' and other fatty acid derivatives with cannabimimetic properties: biochemistry and possible physiopathological relevance. Biochim. Biophys. Acta 1392: 153-175

4. Maccarrone M and Finazzi-Agró A (2002) Endocannabinoids and their actions. Vitam. Horm. 65: 225-255

5. Pertwee RG (2001) Cannabinoid receptors and pain. Prog. Neurobiol. 63: $569-611$
6. Sugiura T, Kobayashi $Y$, Oka S and Waku K (2002) Biosynthesis and degradation of anandamide and 2-arachidonoylglycerol and their possible physiological significance. Prostaglandins Leukot. Essent. Fatty Acids 66: 173-192

7. Hanus L, Abu-Lafi S, Fride E, Breuer A, Vogel Z, Shalev DE, Kustanovich I and Mechoulam R (2001) 2-Arachidonyl glyceryl ether, an endogenous agonist of the cannabinoid CB1 receptor. Proc. Natl. Acad. Sci. USA 98: 3662-3665

8. MacDonald JC and Vaughan CW (2001) Cannabinoids act backwards. Nature 410: $527-530$

9. Wilson RI and Nicoll RA (2002) Endocannabinoid signaling in the brain. Science 296: 678-682

10. Dinh TP, Carpenter D, Leslie FM, Freund TF, Katona I, Sensi SL, Kathuria S and Piomelli D (2002) Brain monoglyceride lipase participating in endocannabinoid inactivation. Proc. Natl. Acad. Sci. USA 99: 10819-10824

11. Hansen HH, Hansen SH, Schousboe A and Hansen HS (2000) Determination of the phospholipid precursor of anandamide and other $\mathrm{N}$-acylethanolamine phospholipids before and after sodium azide-induced toxicity in cultured neocortical neurons. J. Neurochem. 75: 861-871

12. Hillard CJ and Jarrahian A (2000) The movement of $\mathrm{N}$-arachidonoylethanolamine (anandamide) across cellular membranes. Chem. Phys. Lipids 108: $123-134$

13. Maccarrone M, Bari M, Battista N and Finazzi-Agró A (2002) Estrogen stimulates arachidonoylethanolamide release from human endothelial cells and platelet activation. Blood 100: 4040-4048

14. Bracey MH, Hanson MA, Masuda KR, Stevens RC and Cravatt BF (2002) Structural adaptations in a membrane enzyme that terminates endocannabinoid signaling. Science 298: 1793-1796

15. Ueda N, Puffenbarger RA, Yamamoto S and Deutsch DG (2000) The fatty acid amide hydrolase (FAAH). Chem. Phys. Lipids 108: 107-121

16. Deutsch DG, Glaser ST, Howell JM, Kunz JS, Puffenbarger RA, Hillard CJ and Abumrad N (2001) The cellular uptake of anandamide is coupled to its breakdown by fatty acid amide hydrolase (FAAH). J. Biol. Chem. 276: 6967-6973

17. Day TA, Rakhshan F, Deutsch DG and Barker EL (2001) Role of fatty acid amide hydrolase in the transport of the endogenous cannabinoid anandamide. Mol. Pharmacol. 59: 1369-1375

18. Van der Stelt $M$, van Kuik JA, Bari $M$, van Zadelhoff $G$, Leeflang $B R$, Veldink GA, Finazzi Agró A, Vliegenthart JFG and Maccarrone M (2002) Oxygenated metabolites of anandamide and 2-arachidonoyl-glycerol: conformational analysis and interaction with cannabinoid receptors, membrane transporter and fatty acid amide hydrolase. J. Med. Chem. 45: 3709-3720

19. Mukhopadhyay S and Howlett AC (2001) CB1 receptor-G protein association Subtype selectivity is determined by distinct intracellular domains. Eur. J. Biochem. 268: 499-505

20. Reggio PH and Traore H (2000) Conformational requirements for endocannabinoid interaction with the cannabinoid receptors, the anandamide transporter and fatty acid amidohydrolase. Chem. Phys. Lipids 108: 15-35

21. Khanolkar AD, Palmer SL and Makriyannis A (2000) Molecular probes for the cannabinoid receptors. Chem. Phys. Lipids 108: 37-52

22. Jordt SE and Julius D (2002) Molecular basis for species-specific sensitivity to 'hot' chili peppers. Cell 108: 421-430

23. Di Marzo V, Bisogno $T$ and De Petrocellis $L$ (2001) Anandamide: some like it hot. Trends Pharmacol. Sci. 22: 346-349

24. De Petrocellis L, Bisogno T, Maccarrone M, Davis JB, Finazzi-Agró A and Di Marzo V (2001) The activity of anandamide at vanilloid VR1 receptors requires facilitated transport across the cell membrane and is limited by intracellular metabolism. J. Biol. Chem. 276: 12856-12863

25. De Petrocellis L, Melck D, Palmisano A, Bisogno T, Laezza C, Bifulco M and Di Marzo V (1998) The endogenous cannabinoid anandamide inhibits human breast cancer cell proliferation. Proc. Natl. Acad. Sci. USA 95: 8375-8380

26. Melck D, Rueda D, Galve-Roperh I, De Petrocellis L, Guzman M and Di Marzo $\mathrm{V}$ (1999) Involvement of the CAMP/protein kinase A pathway and of mitogenactivated protein kinase in the anti-proliferative effects of anandamide in human breast cancer cells. FEBS Lett. 463: 235-240

27. Melck D, De Petrocellis L, Orlando P, Bisogno T, Laezza C, Bifulco M and Di Marzo V (2000) Suppression of nerve growth factor Trk receptors and prolactin receptors by endocannabinoids leads to inhibition of human breast and prostate cancer cell proliferation. Endocrinology 141: 118-126 
28. Bifulco M, Laezza C, Portella G, Vitale M, Orlando P, De Petrocellis $L$ and $D$ Marzo V (2001) Control by the endogenous cannabinoid system of ras oncogene-dependent tumor growth. FASEB J. 15: 2745-2747

29. Derocq J-M, Bouaboula M, Marchand J, Rinaldi-Carmona M, Ségui M and Casellas P (1998) The endogenous cannabinoid anandamide is a lipid messenger activating cell growth via a cannabinoid receptor-independent pathway in hematopoietic cell lines. FEBS Lett. 425: 419-425

30. Schwarz H, Blanco FJ and Lotz M (1994) Anandamide, an endogenous cannabinoid receptor agonist, inhibits lymphocyte proliferation and induces apoptosis. J. Neuroimmunol. 55: 107-115

31. Sarker KP, Obara S, Nakata M, Kitajima I and Maruyama I (2000) Anandamide induces apoptosis of PC-12 cells: involvement of superoxide and caspase-3. FEBS Lett. 472: 39-44

32. Galve-Roperh I, Sànchez $C$, Cortes ML, Gómez del Pulgar T, Izquierdo M and Guzman M (2000) Anti-tumoral action of cannabinoids: involvement of sustained ceramide accumulation and extracellular signal-regulated kinase activation. Nat. Med. 6: 313-316

33. Sànchez C, Galve-Roperh I, Canova C, Brachet P and Guzman M (1998) Delta ${ }^{9}$-tetrahydrocannabinol induces apoptosis in $\mathrm{C} 6$ glioma cells. FEBS Lett. 436: $6-10$

34. Chan GC-K, Hinds TR, Impey S and Storm DR (1998) Hippocampal neurotoxicity of $\Delta^{9}$-tetrahydrocannabinol. J. Neurosci. 18: 5322-5332

35. Ruiz L, Miguel A and Diaz-Laviada I (1999) Delta9-tetrahydrocannabinol induces apoptosis in human prostate PC-3 cells via a receptor-independent mechanism. FEBS Lett. 458: 400-404

36. Sànchez C, de Ceballos ML, Gómez del Pulgar T, Rueda D, Corbacho C Velasco G, Galve-Roperh I, Huffman JW, Ramon y Cajal S and Guzman M (2001) Inhibition of glioma growth in vivo by selective activation of the $\mathrm{CB}_{2}$ cannabinoid receptor. Cancer Res. 61: 5784-5789

37. Sànchez C, Rueda D, Segui B, Galve-Roperh I, Levade T and Guzman M (2001) The CB1 cannabinoid receptor of astrocytes is coupled to sphingomyelin hydrolysis through the adaptor protein FAN. Mol. Pharmacol. 59: 955-959

38. Rueda D, Galve-Roperh I, Haro A and Guzman M (2000) The CB1 cannabinoid receptor is coupled to the activation of C-Jun $\mathrm{N}$-terminal kinase. Mol. Pharmacol. 58: 814-820

39. Gómez del Pulgar T, Velasco G, Sanchez C, Haro A and Guzman M (2002) De novo-synthesized ceramide is involved in cannabinoid-induced apoptosis. Biochem J. 363: 183-188

40. Gómez del Pulgar T, Velasco G and Guzman M (2000) The CB1 cannabinoid receptor is coupled to the activation of protein kinase B/Akt. Biochem. J. 347: 369-373

41. Gómez del Pulgar T, De Ceballos ML, Guzman M and Velasco G (2002) Cannabinoids protect astrocytes from ceramide-induced apoptosis through the phosphatidylinositol 3-kinase/protein kinase B pathway. J. Biol. Chem. 277: 36527-36533
42. Galve-Roperh I, Rueda D, Gomez del Pulgar T, Velasco G and Guzman M (2002) Mechanism of extracellular signal-regulated kinase activation by the CB1 cannabinoid receptor. Mol. Pharmacol. 62: 1385-1392

43. Maccarrone M, Lorenzon T, Bari M, Melino G and Finazzi-Agró A (2000) Anandamide induces apoptosis in human cells via vanilloid receptors. Evidence for a protective role of cannabinoid receptors. J. Biol. Chem. 275: 31938-31945

44. Wahl GM and Carr AM (2001) The evolution of diverse biological responses to DNA damage: insights from yeast and p53. Nat. Cell Biol. 3: 277-286

45. Esposito G, Ligresti A, Izzo AA, Bisogno T, Ruvo M, Di Rosa M, Di Marzo V and luvone $T$ (2002) The endocannabinoid system protects rat glioma cells against HIV-1 Tat protein-induced cytotoxicity. Mechanism and regulation. J. Biol. Chem. 277: 50348-50354

46. Jacobsson SO, Wallin T and Fowler CJ (2001) Inhibition of rat C6 glioma cell proliferation by endogenous and synthetic cannabinoids. Relative involvement of cannabinoid and vanilloid receptors. J. Pharmacol. Exp. Ther. 299: 951-959

47. Maccarrone M, Cecconi S, Rossi G, Battista N, Pauselli R and Finazzi-Agró A (2003) Anandamide activity and degradation are regulated by early postnatal ageing and follicle-stimulating hormone in mouse Sertoli cells. Endocrinology 144: $20-28$

48. Casanova ML, Blazquez C, Martinez-Palacio J, Villanueva C, FernandezAcenero MJ, Huffman JW, Jorcano JL and Guzman M (2003) Inhibition of skin tumor growth and angiogenesis in vivo by activation of cannabinoid receptors. J. Clin. Invest. 111: 43-50

49. Maccarrone M, Pauselli R, Di Rienzo M and Finazzi-Agró A (2002) Binding, degradation and apoptotic activity of stearoylethanolamide in rat $\mathrm{C} 6$ glioma cells. Biochem. J. 366: 137-144

50. Casaccia-Bonnefil $P$, Kong $H$ and Chao MV (1999) Neurotrophins: the biological paradox of survival factors eliciting apoptosis. Cell Death Differ. 5: 357-364

51. Fernandez-Ruiz J, Berrendero F, Hernandez ML and Ramos JA (2000) The endogenous cannabinoid system and brain development. Trends Neurosci. 23: 14-20

52. Rueda D, Navarro B, Martinez-Serrano A, Guzman M and Galve-Roperh I (2002) The endocannabinoid anandamide inhibits neuronal progenitor cell differentiation through attenuation of the Rap1/B-Raf/ERK pathway. J. Biol. Chem. 277: 46645-46650

53. Williams EJ, Walsh FS and Doherty P (2003) The FGF receptor uses the endocannabinoid signaling system to couple to an axonal growth response. J. Cell Biol. 160: 481-486

54. Bifulco M and Di Marzo V (2002) Targeting the endocannabinoid system in cancer therapy: a call for further research. Nat. Med. 8: 547-550

55. McKallip RJ, Lombard C, Fisher M, Martin BR, Ryu S, Grant S, Nagarkatti PS and Nagarkatti M (2002) Targeting CB2 cannabinoid receptors as a novel therapy to treat malignant lymphoblastic disease. Blood 100: 627-634 